Article

\title{
Analysis of Candidate Idarubicin Drug Resistance Genes in MOLT-3 Cells Using Exome Nuclear DNA
}

\author{
Tomoyoshi Komiyama ${ }^{1, *(1)}$, Atsushi Ogura ${ }^{2}$ (D), Takehito Kajiwara ${ }^{2}$ (1), Yoshinori Okada ${ }^{3}$ \\ and Hiroyuki Kobayashi ${ }^{1, *}$ \\ 1 Department of Clinical Pharmacology, Tokai University School of Medicine, Kanagawa 259-1193, Japan \\ 2 Nagahama Institute of Bio-Science and Technology, Shiga 526-0829, Japan; \\ a_ogura@nagahama-I-bio.ac.jp (A.O.); b312009@m.nagahama-I-bio.ac.jp (T.Ka.) \\ 3 Support Center for Medical Research and Education, Tokai University, Kanagawa 259-1193, Japan; \\ yosi@is.icc.u-tokai.ac.jp \\ * Correspondence: komiyama@tokai-u.jp (T.Ko.); hkobayas@is.icc.u-tokai.ac.jp (H.K.); \\ Tel.: +81-463-93-1121 (T.Ko. \& H.K.)
}

Received: 18 May 2018; Accepted: 16 July 2018; Published: 1 August 2018

\begin{abstract}
Various gene alterations related to acute leukemia are reported to be involved in drug resistance. We investigated idarubicin (IDR) resistance using exome nuclear DNA analyses of the human acute leukemia cell line MOLT-3 and the derived IDR-resistant cell line MOLT-3/IDR. We detected mutations in MOLT-3/IDR and MOLT-3 using both Genome Analysis Toolkit (GATK) and SnpEff program. We found 8839 genes with specific mutations in MOLT-3/IDR and 1162 genes with accompanying amino acid mutations. The 1162 genes were identified by exome analysis of polymerase-related genes using Kyoto Encyclopedia of Genes and Genomes (KEGG) and, among these, we identified genes with amino acid changes. In resistant strains, LIG and helicase plurality genes showed amino-acid-related changes. An amino acid mutation was also confirmed in polymerase-associated genes. Gene ontology (GO) enrichment testing was performed, and lipid-related genes were selected from the results. Fluorescent activated cell sorting (FACS) was used to determine whether IDR permeability was significantly different in MOLT-3/IDR and MOLT-3. The results showed that an IDR concentration of $0.5 \mu \mathrm{g} / \mathrm{mL}$ resulted in slow permeability in MOLT-3/IDR. This slow IDR permeability may be due to the effects of amino acid changes in polymerase- and lipid-associated genes.
\end{abstract}

Keywords: leukemia; MOLT-3; gene polymorphism; genetic variations; idarubicin; drug resistance

\section{Introduction}

We aimed to characterize the molecular mechanisms underlying idarubicin (IDR) resistance in acute leukemia cells. It is known that gene alterations in acute leukemia cells are involved in drug resistance. A better understanding of the mechanisms underlying drug resistance in these cells will help to improve the effectiveness of chemotherapy. In this study, we investigated the mechanisms underlying drug resistance in the human acute leukemia cell line MOLT-3 and its IDR-resistant derivative MOLT-3/IDR by complete nuclear DNA analyses.

In recent years, the mortality rate of leukemia has been gradually decreasing due to increased bone marrow transplantations; development of antibiotic, antifungal, and antiviral drugs; optimization of transfusion therapy; analysis of treatment protocols by multicenter studies; and development of molecularly targeted drugs [1,2]. In general, IDR, an anthracycline antitumor agent, is used as a therapeutic agent for acute myelogenous leukemia. IDR has also been used for acute myeloid leukemia, blast crisis of chronic myelogenous leukemia, and recurrence of acute lymphocytic 
leukemia. IDR has a superior remission induction effect than daunorubicin, and remission induction therapy using idarubicin was reported to be effective in clinical trials of recurrent acute lymphocytic leukemia [3]. IDR acts by inhibiting the transcription of RNA from DNA, which in turn prevents the growth of cancer cells. Moreover, IDR is highly lipophilic and can therefore maintain a high intracellular drug concentration even in P-glycoprotein-expressing cells. However, antitumor drug resistance in solid and recurring tumors has decreased the effectiveness of antitumor drugs $[1,2,4]$. As patients with leukemia often respond differently to treatment, IDR resistance is becoming an increasing problem and a significant barrier in treating patients. Therefore, understanding of the IDR resistance mechanism will be useful for the development of molecular targeted drugs in the future.

Since 1995, we have conducted many experiments using the MOLT-3 cell line to determine the genetic cause of IDR resistance. We have previously created cultures of various tumor cell lines that are resistant to many antitumor drugs, including anthracycline [5-8]. We also analyzed the molecular mechanisms underlying resistance in these cells to identify mutations or abnormal expression of drug resistance genes [9-17]. We have shown that it is possible to overcome drug resistance by using nucleic acid formations to suppress the expression of the genes that contribute to drug resistance. Abnormal activation of kinase pathways has been observed in a range of malignant tumors, as well as in some resistant cells. Furthermore, it has been confirmed that it is possible to overcome resistant cells by suppressing small interfering RNA (siRNA) or nucleic acid preparation in kinase pathways [15]. Analysis of the biomarkers associated with drug response may be useful for treating cancer. We previously analyzed these biomarkers using cell panels treated with antitumor agents and opioid analgesics, which are major obstacles in managing cancer treatment [18-20].

Recently, we identified putative drug resistance genes using comparative genomic hybridization (CGH) array and whole mitochondrial DNA sequence analyses [21]. We identified a unique mutation site (p.Thr61Ile) in the ND3 gene of mitochondrial DNA in the MOLT-3/IDR cell line. From CGH array analysis, we extracted five candidate drug resistance genes and focused specifically on the GALNT2 gene involved in O-linked glycosylation of lipids. A mutation in the stop codon of GALNT2 leads to 18 additional amino acids being translated in the mutated protein compared with the wild-type. However, we could not obtain a detailed evaluation at the single-nucleotide polymorphism (SNP) level or mutated amino acid level. Our aim is to develop a method to overcome drug resistance by combining nucleic acid formulation and inhibitors that target important resistance factors.

To understand the cause of drug resistance, we investigated the underlying mechanisms using nuclear DNA analyses of the exomes of MOLT-3 and MOLT-3/IDR cells. In addition, we attempted to identify mutations in MOLT-3/IDR and MOLT-3 cells by using both Genome Analysis Toolkit (GATK) and SnpEff program [22]. Exome analysis is a method of comprehensive analysis using only exon sequences, which is used in gene resistance analyses. For example, some researchers have induced the disappearance of SNPs and the emergence of new SNPs, suggesting that the emergence of drug-resistant clones from patient genes is possible [23-31].

In the future, we aim to target certain expression factors and gene mutations in resistant cells to identify possible causes of differential cancer gene expression, independent of normal cells.

\section{Materials and Methods}

\subsection{Generation of MOLT-3/IDR Cell Lines}

To study the mechanism underlying IDR resistance, an IDR-resistant cell line was established from the human acute leukemia cell line MOLT-3 (American Type Culture Collection (ATCC), Manassas, VA, USA) [18]. MOLT-3 cells were treated with $40 \mathrm{nM}$ IDR (Idamycin, Pfizer, New York, NY, USA) for $8 \mathrm{~h}$, at which point the surviving cells were subcultured weekly with IDR. The concentration of IDR was increased by $20 \mathrm{nM}$ at each exposure [32]. After 4 months, IDR resistance was tested by 3-(4,5-dimethylthiazol-2-yl)-2,5-diphenyltetrazolium bromide (MTT) assay, and the cells were found to be 10 times more resistant to IDR. These cells were designated MOLT-3/IDR (Table S1) [21]. 
Single colonies were subcultured and retested by MTT assay before cryopreservation. After thawing, the cells were cultured for 1 month before use in subsequent experiments.

Similar attempts were undertaken to establish IDR-resistant subclones from the cell lines K562 and CCRF-CEM(CEM) to overcome concerns regarding instability in the MOLT3 system. However, increasing the resistance by 10 -fold in these cell lines was difficult.

\subsection{Cell Lines and Culture Conditions}

MOLT-3 and MOLT-3/IDR (ATCC) cells were cultured in Roswell Park Memorial Institute (RPMI) 1640 Medium (Nacalai Tesque, Kyoto, Japan) containing penicillin (50 IU/mL) and streptomycin $(50 \mu \mathrm{g} / \mathrm{mL})$ and supplemented with $10 \%$ fetal calf serum. MOLT-3 and MOLT-3/IDR cells were cultured for 2 days at a density of $1.6 \times 10^{6}$ cells $/ 8 \mathrm{~mL}$ RPMI1640 culture medium per $100 \mathrm{cc}$ cell culture dish (Eppendorf, Hamburg, Germany).

\subsection{Exome Analysis of MOLT-3 and MOLT-3/IDR}

We performed exome analysis to investigate the IDR resistance mechanism in MOLT-3 and MOLT-3/IDR cells. Exomes of DNA samples were enriched using previously captured platforms obtained using the SureSelect XT Reagent Kit and SureSelect XT Human All Exon V5 (Agilent Technologies, Santa Clara, CA, USA) and assembled using the SeqNovaCS Data Analysis System at Hokkaido System Science Co., Ltd. (Sapporo, Japan). Prepared libraries were then sequenced with $2 \times 100$ bp paired-end reads on Hiseq1000 and HiSeq 2500 sequencers (Illumina, San Diego, CA, USA).

For mutational analysis, we used the GATK tool [33]. The Unified Genotyper GATK tool was used to identify mutant genotypes in both MOLT-3 and MOLT-3/IDR. Using hg38 obtained from the University of California (Santa Cruz, CA, USA) as a reference, we identified mutation sites within the genotypes of each sample. In addition, we annotated our findings in SnpEff [22]. For the identified mutations, we confirmed the information already available in the database, such as the presence or absence of the gene or amino acid mutations. Based on information obtained from the SnpEff [34] annotation, we compared the mutations detected in MOLT-3 and MOLT-3/IDR cells and identified genes with mutations accompanied by specific amino acid mutations in MOLT-3/IDR cells. We created a script for the extraction of these genes, and then investigated the genes that were assumed to be related to IDR resistance mechanisms.

\subsection{KEGG Pathway Analysis}

IDR has been shown to inhibit nuclear polymerase activity, potentially by cutting one or both strands of double-stranded DNA before inhibiting recombination by the enzyme topoisomerase II. Therefore, we performed Kyoto Encyclopedia of Genes and Genomes (KEGG) pathway analysis to reveal the functions of polymerase-related genes and other specific mutated genes [35]. The selected pathways were used as DNA replication pathways for complex network analysis of proteins and enzymes that play a role in and are required for DNA replication.

\subsection{GO Enrichment Test}

Identified genes were used to perform the gene ontology (GO) enrichment test using the gene ontology enrichment analysis and visualization tool (GOrilla) [36]. The GOrilla enrichment test allocates an Ensembl ID to each gene based on the information about gene function provided by the GO test. Within a set of detected genes, common functions become apparent by studying gene relationships. This system allowed us to visualize gene relationships by comparing many functions within a set of detected genes. The reference was set to Homo sapiens, and enrichment tests were performed using the single ranked list of genes. The $p$-value threshold was set at $10^{-3}$. 


\subsection{Drug Treatment}

IDR was dissolved in an Otsuka distilled water solution (Otsuka, Osaka, Japan). After 2 days of culturing, MOLT-3 and MOLT-3/IDR cells were suspended in RPMI 1640 culture medium in a 24-well culture plate (Eppendorf) with the density adjusted to $2 \times 10^{5}$ cells $/ \mathrm{mL} /$ well. MOLT-3 and MOLT-3/IDR cells were cultured without (control) or with IDR $(0.1,0.5$, and $1 \mathrm{mg} / \mathrm{mL}$ ) for $10 \mathrm{~min}$.

\subsection{Flow Cytometric Analysis}

Concentration experiments were conducted according to the method described by Smeets et al. [32]. IDR was used at concentrations of $0,1,10$, and $50 \mu \mathrm{g} / \mathrm{mL}$; it was added to the cells and cells were washed within $60 \mathrm{~min}$. In the preliminary experiment, cells were recovered by trypsinization; $1 \mathrm{~mL}$ of the medium containing cells was centrifuged; the supernatant was separated using a pipette; $1 \mathrm{~mL}$ PBS was added; the mixture was then centrifuged and aspirated; further, $300 \mu \mathrm{l}$ PBS was added; and lastly, the mixture was subjected to fluorescent activated cell sorting (FACS) analysis. This experiment was repeated twice. Based on the results, we selected a concentration of $1 \mu \mathrm{g} / \mathrm{mL}$, which compared between the MOLT 3 cells and IDR cells. Because of this reaction, we performed another detailed test with the three concentrations $0,0.1$, and $0.5 \mu \mathrm{g} / \mathrm{mL}$, with one set for $30 \mathrm{~min}$ and the other set for $10 \mathrm{~min}$. After IDR treatment, the cells were recovered by trypsinization; $1 \mathrm{~mL}$ of the medium containing treated cells was subjected to centrifugation; the supernatant was aspirated; $1 \mathrm{~mL}$ medium was again added, and the mixture was centrifuged; the supernatant was removed, $300 \mu \mathrm{L}$ medium was added; and lastly, the mixture was subjected to FACS analysis. In addition, time from the point of washing was also considered. Measurements were done at 0, 30, and $90 \mathrm{~min}$; in the intermittent period, the mixture was incubated in a $\mathrm{CO}_{2}$ incubator. After $10 \mathrm{~min}$ of incubation, the cells were washed twice with RPMI 1640 culture medium and added to $300 \mu \mathrm{L}$ of RPMI 1640 culture medium in $5 \mathrm{~mL}$ Falcon round-bottom polystyrene tubes (CONING, New York, NY, USA). IDR quantification was performed using a BD Fortessa cytometry analyzer (Beckton Dickinson, San Jose, CA, USA) and analyzed with FlowJo version 7.6.5 software (TreeStar, San Carlos, CA, USA).

\section{Results}

\subsection{Detection of Mutations Using GATK and SnpEff}

We detected mutations by comparing the exome sequence data (MOLT-3 and MOLT-3/IDR) with the reference genome using GATK. For this, we did not map MOLT-3 and MOLT-3/IDR directly when attempting to identify the mutations, as both MOLT-3 and MOLT-3/IDR cells contain fragmented short-leads.

We then annotated the detected mutations using SnpEff and compared the mutations detected in MOLT3 and MOLT-3/IDR cells according to the annotated information. This procedure is shown in Figure 1. Further, we extracted the mutated genes and genes with amino acid changes from both MOLT-3 and MOLT-3/IDR cells. We also extracted specific genes only found in MOLT-3/IDR and specific genes with amino acid changes, and determined the number of mutations in specific amino acid sequences by comparison. The results are summarized in Table 1 and are labeled as mutations in MOLT-3, mutations in IDR-MOLT3, and number of specific mutations in MOLT-3/IDR. Specific mutations in MOLT-3/IDR were obtained by comparing MOLT-3 and MOLT-3/IDR, and extracting the mutations that occur specifically in MOLT-3/IDR. The total number of mutations increased with the number of genes in the category, including splicing variants, noncoding genes, and predicted genes. Consequently, we identified 8839 genes with specific mutations and 1162 genes with accompanying amino acid mutations in MOLT-3/IDR cells (Tables S2 and S3). In addition, 5124 mutated amino acids were found to exist specifically in MOLT-3/IDR cells. 
Table 1. Genome Analysis Toolkit (GATK) and SnpEff mutant analysis.

\begin{tabular}{cccc}
\hline & MOLT-3 & MOLT-3/IDR & MOLT-3/IDR only \\
\hline Mutant base & 286,781 & 318,539 & 194,683 \\
Mutant genes & 47,520 & 49,712 & 8839 \\
Genes containing amino acid changes & 12,452 & 12,906 & 1162 \\
Endemic amino acids & 33,712 & 36,489 & 5124 \\
\hline
\end{tabular}

GATK: Genome Analysis Toolkit; SnpEff: SNP effect; IDR: idarubicin

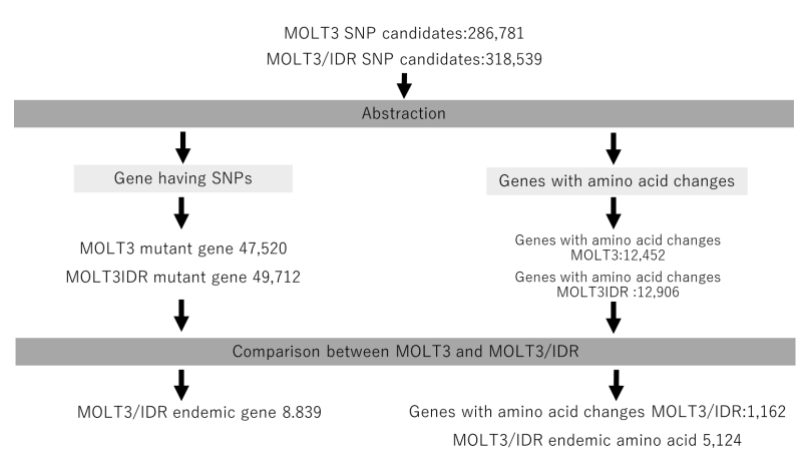

Figure 1. Procedure for identifying specific gene mutations. We extracted mutated genes and genes with amino acid changes from both MOLT-3 and MOLT-3/IDR cells. In addition, we extracted specific genes that only existed in MOLT-3/IDR cells and specific genes with amino acid changes, and then determined the number of mutations in specific amino acids by comparing them. SNP: Single Nucleotide Polymorphism.

\subsection{Results of KEGG Pathway Analysis}

In addition to inhibiting nuclear polymerase activity, IDR cuts DNA strands by inhibiting the enzyme topoisomerase II, which recombines DNA by cutting one or both strands of double-stranded DNA. Using this mechanism, we examined mutations of polymerase-related genes and identified 1162 genes from exome analysis, which were then investigated by KEGG pathway analysis. We then identified genes containing the expected amino acid changes (Table S2).

Figure 2 shows the classification of the identified genes into the three groups: DNA replication genes, genes related to protein functions, and genes related to transcription. Circles indicate genes with amino acid changes. We did not observe any amino acid changes or gene mutations related to topoisomerase. However, it is possible that common mutations were removed among MOLT-3/IDR and MOLT- 3 cells. For these mutations, we analyzed amino acid changes in the domain using the Uniprot database. Mutations were identified in polymerase-related genes associated with the observed amino acid changes. However, we did not detect mutations in any domain. Nevertheless, given the effect of IDR, we can consider that provided the mutations were found in genes, IDR is somehow involved (Table 2).

Table 2. Genes with polymerase-related amino acid changes.

\begin{tabular}{cccc}
\hline Gene & Mutant Amino Acid & Domain & Known or Unknown \\
\hline LIG1 & p.Lys702Glu & $\times$ & $\times$ \\
\hline \multirow{2}{*}{ MCM3 } & p.Ile3Leu & $\times$ & $\times$ \\
& p.Asp391Gly & MCM & $\times$ \\
& p.Ala620Pro & $\times$ & $\times$ \\
\hline \multirow{2}{*}{ MCM7 } & p.Val273Ile & $\times$ & $\times$ \\
\multirow{2}{*}{ RFC1 } & p.Gly416Asp & BRCT & $\times$ \\
& p.Leu612Pro & $\times$ & $\times$ \\
\multirow{2}{*}{ RNASEH2B } & p.Phe95Cys & $\times$ & $\times$ \\
& p.Ala287Ser & $\times$ & $\times$ \\
\hline
\end{tabular}

BRCT: Breast cancer 1 C-terminal 


\subsection{Analysis of Genes Using the Gene Ontology Enrichment Test}

One aim of this study was to determine the most common functions in a set of 1162 genes identified by exome analysis. To achieve this, GOrilla was used to analyze biological processes and cell structure/molecular functions [37]. Further, in vivo processes related to gene function were visualized based on the annotation of each gene. mutations were removed in MOLT-3/IDR and MOLT-3 cells.

Figure 3 shows the relationships and related processes of a single identified gene; the lower the $p$-value, the larger the difference in expression level compared with the reference. The $p$-values are color-coded as described in the figure legend. The second graph was created by considering the processes with the lowest $p$-values from the lower layer of each extracted process and then displaying it as a graph. The ID shows its location in Figure 3. ID4 mainly represents removed processes that are related to fatty acids, as well as one process that was removed regardless of the $p$-value as an example. This was not used in the analysis. Of the processes removed, five were involved in the metabolism of fatty acids (Table 3).

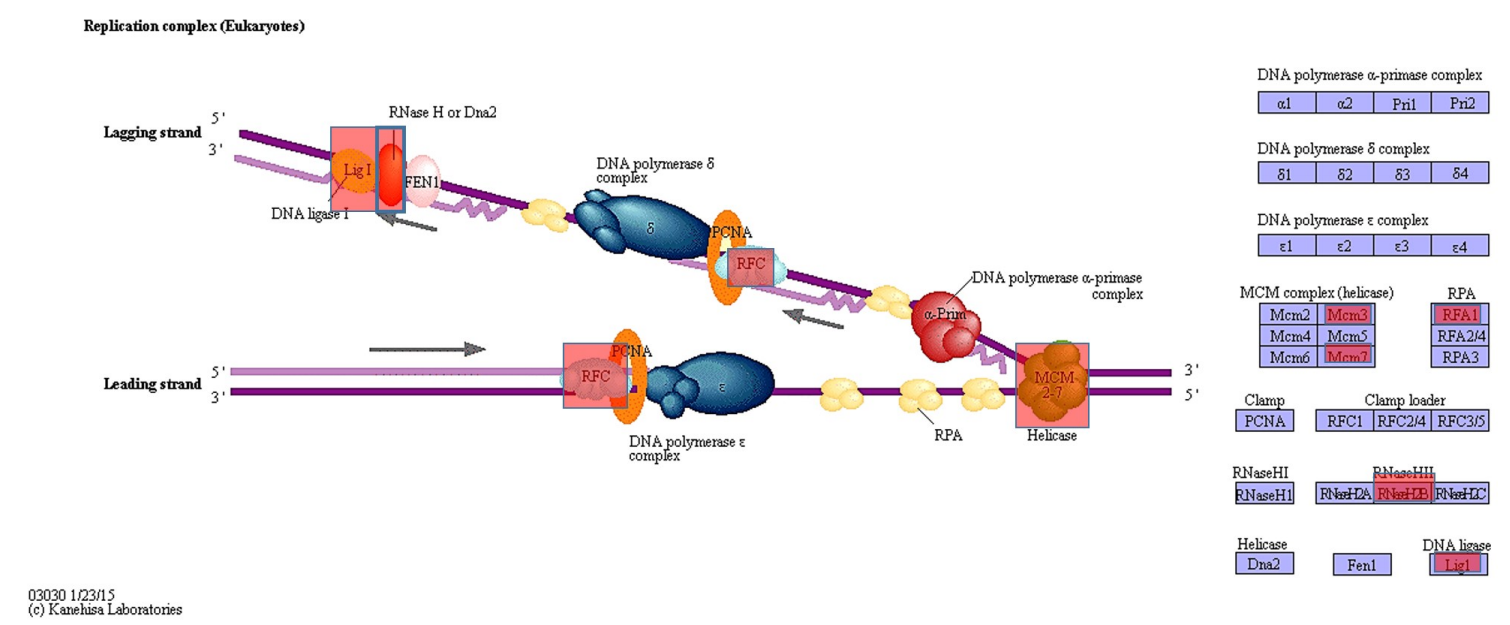

Figure 2. Polymerase-related genes identified using Kyoto Encyclopedia of Genes and Genomes (KEGG) pathway analysis. DNA replication of genes related to protein functions and genes related to transcription are shown. Circles indicate genes with amino acid changes. We did not observe any amino acid changes or gene mutations in topoisomerase genes. However, it is possible that common mutations were removed in MOLT-3/IDR and MOLT-3 cells. Adapted from [35].

According to the Cancer Chemotherapy Center [38], newly synthesized fatty acids thrive despite containing numerous exogenous lipids, and a number of lipid metabolism enzymes, including fatty acid synthase, contribute to cancer development and transformation. In particular, the fatty acid metabolism enzyme acyl-COA synthetase acts as an inhibitory agent in the mitochondria-dependent intrinsic apoptotic pathway. This has been found to impact cancer survival rates and resistance to drugs. Therefore, it is believed that variations in lipid-related genes that include fatty acids may be related to IDR tolerance levels. To confirm this, a GO enrichment test was performed, which included the previously removed processes and lipid-related genes selected from the results. The selected genes are shown in Table 4. Uniprot was used to determine whether domain amino acids changed in the removed genes. We found that domain amino acids were altered in adiponectin (ADIPOQ), arachidonate 5-lipoxygenase (ALOX5), and ALOX15 genes. The C1 domain in ADIPOQ and lipoxygenase domain amino acids in ALOX5 and ALOX15 were found to be altered. ADIPOQ is related to lipid oxidation, fatty acid oxidation, fatty acid catabolism, lipid modification, and lipid metabolism [39-48]. ALOX5 is also related to lipid metabolism [49-53]. ADIPOQ, ALOX5, and ALOX15 are reportedly associated with lung cancer, colorectal cancer, and colon cancer [54-58]. In particular, ALOX5 has attracted increasing attention as a key gene for drug targeting and overcoming drug resistance in patients with leukemia [59-67]. 
Mutations associated with amino acids in lipid-related genes and mutations in the domains of amino-acid-related genes were also present.

\subsection{Analysis of IDR Permeability in MOLT-3/IDR and MOLT-3 Cells by FACS}

Numerous mutations in lipids and plasma membrane proteins were detected by the GO enrichment test. Subsequently, FACS was used to study IDR permeability in MOLT-3/IDR and MOLT-3 cells (Table S4). IDR was used at concentrations of $0,0.1$, and $0.5 \mu \mathrm{g} / \mathrm{mL}$ for 0,30 , and $90 \mathrm{~min}$ after the washing step. IDR was administered after incubation for $10 \mathrm{~min}$. The measurements were recorded 12 times in total over 2 days, with the results shown in Figure 4, Figure 5, and Figure 6. An IDR concentration of $0.5 \mu \mathrm{g} / \mathrm{mL}$ was found to significantly slow the drug's permeability ( $p$-value $=0.001$ ) in MOLT-3/IDR cells compared with that in MOLT-3 cells. Furthermore, IDR permeability was also slow in MOLT-3/IDR cells at 0 min after washing ( $p$-value $=0.029 ; p$-value $<0.05)$. Our results confirmed that an IDR concentration of $0.5 \mu \mathrm{g} / \mathrm{mL}$ resulted in the slowest permeability in MOLT-3/IDR cells immediately after administration at $0 \mathrm{~min}$ after washing. After incubation for 30 and $90 \mathrm{~min}$, cells treated with $0.5 \mu \mathrm{g} / \mathrm{mL}$ IDR showed slightly slow permeability. This difference in permeability is believed to be related with IDR resistance. In addition, the fluorescence intensity of IDR permeability of the MOLT- 3 cells at a concentration of $0.5 \mu \mathrm{g} / \mathrm{mL}$ was higher than that of the MOLT-3/IDR cells.

Table 3. GO enrichment test results.

\begin{tabular}{cccc}
\hline ID & Description & $p$-Value & Number of Genes \\
\hline 1 & fatty acid beta-oxidation & $1.63 \times 10^{-5}$ & 3 \\
2 & regulation of cellular carbohydrate metabolic process & $4.08 \times 10^{-5}$ & 5 \\
1 & lipid oxidation & $4.22 \times 10^{-5}$ & 3 \\
1 & fatty acid oxidation & $4.22 \times 10^{-5}$ & 3 \\
1 & fatty acid catabolic process & $4.22 \times 10^{-5}$ & 3 \\
1 & fatty acid beta-oxidation using acyl-CoA dehydrogenase & $5.28 \times 10^{-5}$ & 2 \\
3 & response to tumor necrosis factor & $6.70 \times 10^{-5}$ & 6 \\
4 & negative regulation of plasma membrane long-chain fatty acid transport & $5.28 \times 10^{-4}$ & 2 \\
\hline
\end{tabular}

Table 4. Lipid-related genes.

\begin{tabular}{cccc}
\hline Gene & Mutant Amino Acid & Domain & Known or Unknown \\
\hline ACOX2 & p.Lys66Thr & $\times$ & $\circ$ \\
ACAD10 & p.Arg69Cys & $\times$ & $\times$ \\
ADIPOQ & p.Tyr216His & $\mathrm{c} 1 \mathrm{q}$ & $\times$ \\
AGK & p.Thr2Met & $\times$ & $\times$ \\
ALOX15 & p.Asn237Ser & Lipoxygenase & $\times$ \\
ALDH3A2 & p.Leu479Arg & $\times$ & $\times$ \\
AGPAT9 & p.Glu321Gln & $\times$ & $\times$ \\
ALOX5 & p.Asp465Val & Lipoxygenase & $\times$ \\
ABHD3 & p.Asp291Tyr & $\times$ & $\times$ \\
\hline
\end{tabular}




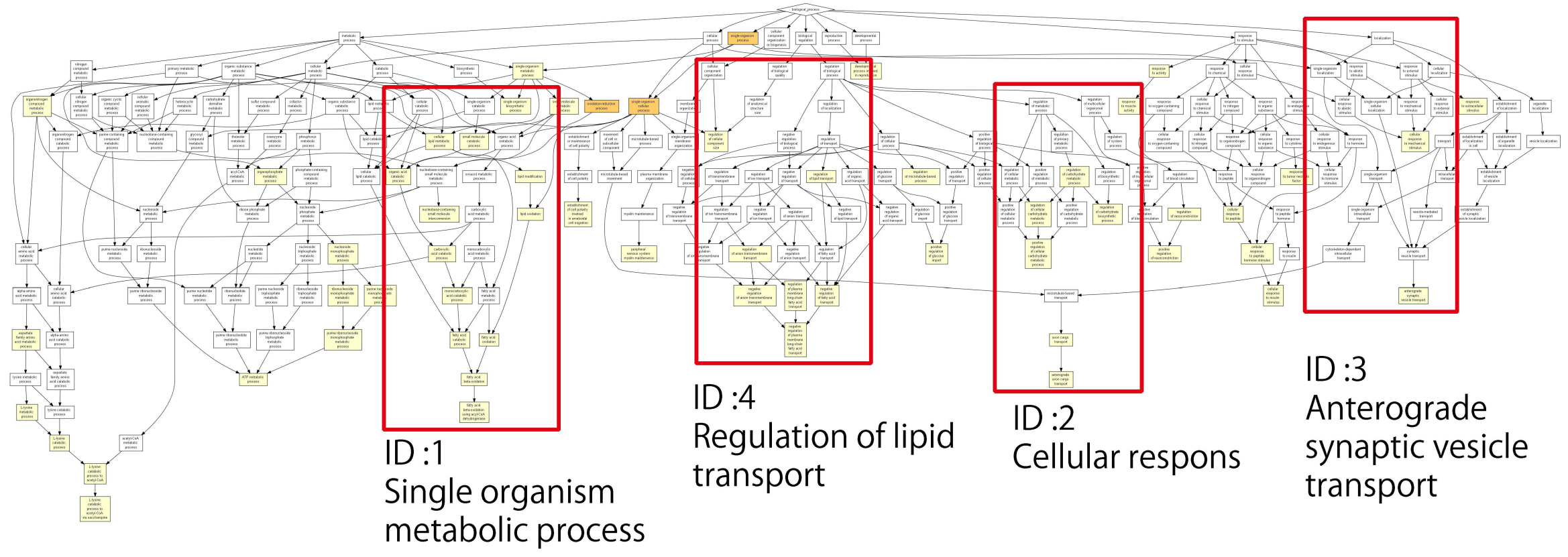

Figure 3. Functional analysis using the Gene Ontology (GO) enrichment test. The related processes and relationships of a number of identified genes are shown. The lower the $p$-value, the larger the difference in expression level compared with the reference. $p$-values are color coded as follows: white, $>10^{-3}$; light orange, $10^{-3}$ to $10^{-5}$; orange, $10^{-5}$ to $10^{-7}$; dark orange, $10^{-7}$ to $10^{-9}$; red, $<10^{-9}$. The next graph was created by considering the process with the lowest $p$-value from the lower layer of each extracted process and then displaying it in a graph. The ID shows its location in Figure 3. ID4 mainly represents the removed processes that relate to fatty acids, and also one process that was removed regardless of its $p$-value as an example. 


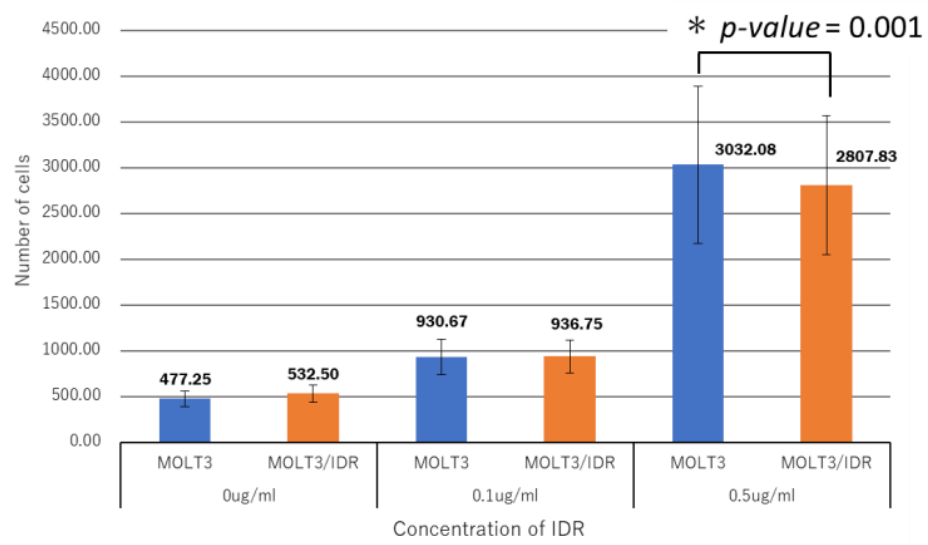

Figure 4. Analysis of idarubicin (IDR) permeability at concentrations of $0,0.1$, and $0.5 \mu \mathrm{g} / \mathrm{mL}$ IDR in MOLT-3/IDR and MOLT-3 cells by fluorescent assisted cell sorting (FACS). Immediately after administration, the MOLT-3/IDR cells treated with $0.5 \mu \mathrm{g} / \mathrm{mL}$ IDR showed slow IDR permeability.

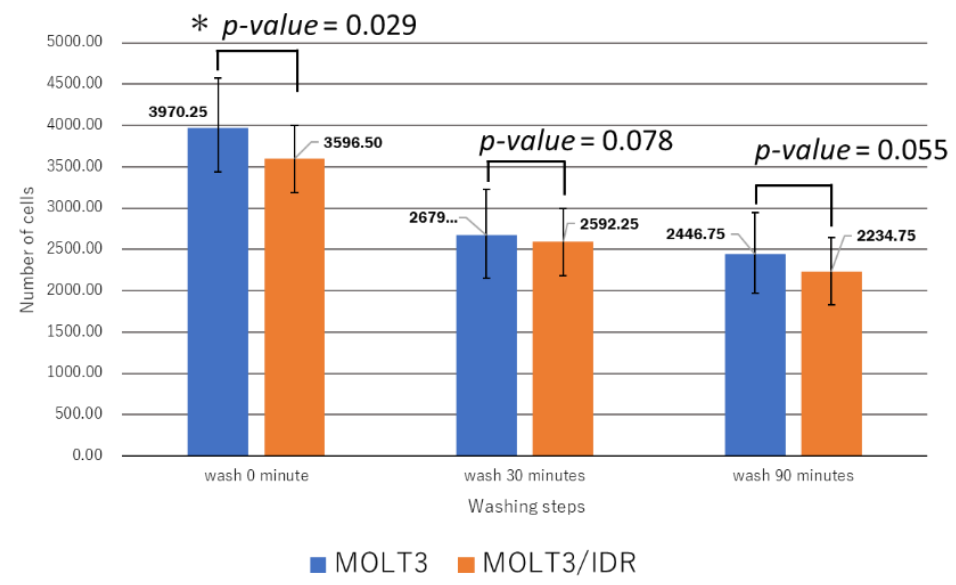

Figure 5. Analysis of IDR permeability according to differences in administration time in MOLT-3/IDR and MOLT-3 cells by FACS. After 0, 30, and 90 min incubation of MOLT-3/IDR cells with $0.5 \mu \mathrm{g} / \mathrm{mL}$ IDR, the permeability was slightly slower. In particular, IDR permeability at $0 \mathrm{~min}$ after washing was the slowest in MOLT-3/IDR cells ( $t$-test, $p$-value $=0.029 ; p$-value $<0.05, t$-test).

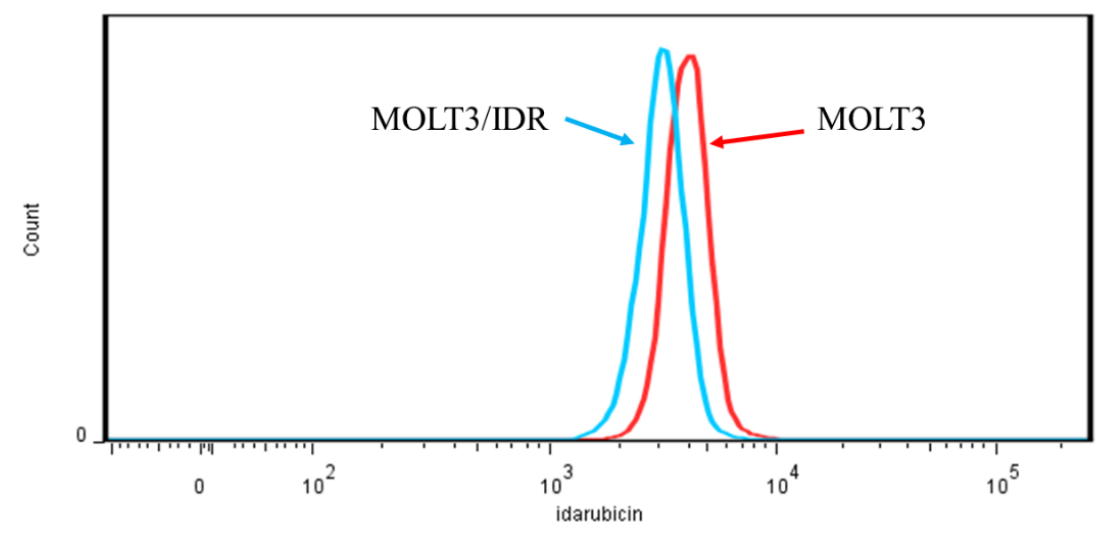

Idarubicin (0.5ug)

Figure 6. Histogram plots of IDR permeability at a concentration of $0.5 \mu \mathrm{g} / \mathrm{mL}$ in MOLT-3/IDR and MOLT-3 cells. 


\section{Discussion}

In the current study, we investigated the molecular mechanisms underlying IDR resistance using the human T cell leukemia cell line MOLT-3 and its IDR-resistant derivative MOLT-3/IDR. We attempted to identify genes specifically mutated in MOLT-3/IDR cells by both mitochondrial and nuclear DNA analyses.

GATK mutation detection and annotation using SnpEff helped us identify genes associated with amino acid changes. Given the active mechanism of IDR, it was hypothesized that polymerase-related genes would also contain mutations. KEGG pathway analysis showed that $L I G$ and helicase plurality genes contained amino-acid-related alterations in resistant strains. Furthermore, amino acid mutations were also found in polymerase-associated genes, but not in the domains. This suggests that while gene function remained unchanged, IDR active sites in the genes were altered, preventing the drug from functioning normally. This may be related to the development of IDR resistance.

Next, a GO enrichment test was performed using GOrilla, in which genes with mutated amino acids were linked to GO terms and the biological processes related to each gene were determined. We found that a large number of genes were related to fatty acid and lipid metabolism. In cancer cells, de novo synthesis of fatty acids thrives regardless of exogenous lipid levels. Through fatty acid synthesis, enzymes associated with acyl-CoA synthetase, lipid metabolism, and fatty acid metabolism promote cancer development and growth. Given their relationship with cancer survival and drug resistance, the detected genes were examined further. We found a large number of genes associated with amino acid mutations in the domain. In addition, mutations resulting in amino acid changes were found in polymerase- and lipid-associated genes.

FACS was then used to determine whether IDR permeability differed significantly between MOLT-3/IDR and MOLT-3 cells, with the results showing that an IDR concentration of $0.5 \mu \mathrm{g} / \mathrm{mL}$ resulted in slow IDR permeability in MOLT-3/IDR cells. In addition, the fluorescence intensity of IDR permeability in the MOLT-3/IDR cells at a concentration of $0.5 \mu \mathrm{g} / \mathrm{mL}$ was lower than that in MOLT cells. This is considered to be a factor indicating resistance. Kapli et al. addressed this by showing that sensitive cells accumulated more drug and showed at least 2-fold greater levels of brightness than the resistant cells [68]. This is believed to be due to the effects of amino acid changes in polymeraseand lipid-associated genes. Whether this is indeed related to the acquisition of IDR resistance will be a topic of a future study; however, the discovery of a number of genes likely related to IDR resistance implies that significant progress has been made in leukemia research in relation to the understanding of the mechanisms behind the acquisition of IDR resistance.

Further studies should focus on the mechanism underlying IDR resistance acquisition to determine whether it is related to amino acid changes. Furthermore, we believe that using the $\mathrm{K} 562$ and CEM cell line, we would like to confirm the results obtained in our analyses the same way. We aim to undertake such research and provide new information on the acquisition of IDR resistance.

The results of the current study will broaden our knowledge on the genetic diversity of the mechanisms associated with drug resistance and genomic and gene correlation research. Moreover, we believe that our research will contribute to next-generation genetics. The use of new bioinformatics technology will form the basis of next-generation cancer genetics research.

\section{Conclusions}

We detected mutations in MOLT-3/IDR and MOLT-3 cells using both GATK and SnpEff. Subsequently, we identified 8839 genes with specific mutations in MOLT-3/IDR cells and 1162 genes accompanied with amino acid mutations. Among the 1162 genes, genes related to polymerases, fatty acid synthesis, and lipid metabolism showed nonsynonymous mutations, suggesting that these genes are related to IDR permeability. FACS was used to determine whether the permeability of IDR was significantly different between MOLT-3/IDR and MOLT-3 cells. The results showed that although there was no significant difference between the two cells, an IDR concentration of $0.5 \mu \mathrm{g} / \mathrm{mL}$ resulted in slow IDR permeability in MOLT-3/IDR cells. This may be due to the effects of amino acid changes 
found in polymerase- and lipid-associated genes. Taken together, our findings suggest that multiple mutations in the genes identified in the current study are involved in IDR resistance. In the future, we intend to analyze the roles of these genes in IDR resistance in leukemia cells in greater depth by using targeted inhibitors, cell proliferation, and IDR sensitivity assays.

Supplementary Materials: The following are available online at http:/ /www.mdpi.com/2073-4425/9/8/390/s1. Table S1: Levels of IDR resistance in MOLT-3 and MOLT-3/IDR cells. Table S2: Genes specific to MOLT-3/IDR cells (8839 genes). Table S3: Genes with amino acid mutations specific to MOLT-3/IDR cells (1162 genes). Table S4: Raw data for IDR Permeability in MOLT-3 and MOLT-3/IDR cells using FACS.

Author Contributions: T.K. (Tomoyoshi Komiyama) and H.K. conceived the study and designed the experiments. A.O. and T.K. (Takehito Kajiwara) performed the exome analysis. Y.O. performed the flow cytometric analysis; T.K. (Tomoyoshi Komiyama) and H.K. verified the results and wrote the paper. All the authors have read and approved the final draft of the manuscript.

Funding: This work was supported by KAKENHI (15K08109). The funders had no role in study design, data collection and analysis, decision to publish, or preparation of the manuscript.

Acknowledgments: We are grateful to the Support Center for Medical Research and Education of Tokai University for their technical assistance.

Conflicts of Interest: The authors declare they have no competing interests.

Ethics Approval and Consent to Participate: The established cell line was handled according to the genome guidelines of the Japanese Ministry of Education. This study was conducted in accordance with the provisions of the ethics committee of Tokai University School of Medicine.

\section{References}

1. Saultz, J.N.; Garzon, R. Acute Myeloid Leukemia: A Concise Review. J. Clin. Med. 2016, 5, 33. [CrossRef] [PubMed]

2. Board PATE. Adult Acute Lymphoblastic Leukemia Treatment $\left(\mathrm{PDQ}^{\circledR}\right)$. PDQ Cancer Information Summaries; 2018. Available online: https:/ / www.cancer.gov / (accessed on 20 July 2018).

3. Koh, K.-N.; Im, H.J.; Kim, H.; Kang, H.J.; Park, K.D.; Shin, H.Y.; Ahn, H.S.; Lee, J.W.; Yoo, K.H.; Sung, K.W.; et al. Outcome of Reinduction Chemotherapy with a Modified Dose of Idarubicin for Children with Marrow-Relapsed Acute Lymphoblastic Leukemia: Results of the Childhood Acute Lymphoblastic Leukemia (CALL)-0603 Study. J. Korean Med. Sci. 2017, 32, 642-649. [CrossRef] [PubMed]

4. Kobayashi, H.; Dorai, T.; Holland, J.F.; Ohnuma, T. Reversal of drug sensitivity in multidrug-resistant tumor cells by an MDR1 (PGY1) ribozyme. Cancer Res. 1994, 54, 1271-1275. [PubMed]

5. Masuda, Y.; Kobayashi, H.; Holland, J.F.; Ohnuma, T. Reversal of multidrug resistance by a liposome-MDR1 ribozyme complex. Cancer Chemother. Pharmacol. 1998, 42, 9-16. [CrossRef] [PubMed]

6. Kobayashi, H.; Takemura, Y.; Miyachi, H. Molecular characterization of human acute leukemia cell line resistant to ZD9331, a non-polyglutamatable thymidylate synthase inhibitor. Cancer Chemother. Pharmacol. 1998, 42, 105-110. [CrossRef] [PubMed]

7. Takemura, Y.; Kobayashi, H.; Gibson, W.; Kimbell, R.; Miyachi, H.; Jackman, A.L. The influence of drug-exposure conditions on the development of resistance to methotrexate or ZD1694 in cultured human leukaemia cells. Int. J. Cancer 1996, 66, 29-36. [CrossRef]

8. Kobayashi, H.; Takemura, Y.; Ohnuma, T. Relationship between tumor cell density and drug concentration and the cytotoxic effects of doxorubicin or vincristine: Mechanism of inoculum effects. Cancer Chemother. Pharmacol. 1992, 31, 6-10. [CrossRef] [PubMed]

9. Matsushita, H.; Kizaki, M.; Kobayashi, H.; Ueno, H.; Muto, A.; Takayama, N.; Awaya, N.; Kinjo, K.; Hattori, Y.; Ikeda, Y. Restoration of Retinoid Sensitivity by MDR1 Ribozymes in Retinoic Acid-Resistant Myeloid Leukemic Cells. Blood 1998, 91, 2452-2458. [PubMed]

10. Miyachi, H.; Takemura, Y.; Kobayashi, H.; Ando, Y. Expression of variant dihydrofolate reductase with decreased binding affinity to antifolates in MOLT-3 human leukemia cell lines resistant to trimetrexate. Cancer Lett. 1995, 88, 93-99. [CrossRef]

11. Kobayashi, H.; Takemura, Y.; Ohnuma, T. Variable expression of RFC1 in human leukemia cell lines resistant to antifolates. Cancer Lett. 1998, 124, 135-142. [CrossRef] 
12. Suwanai, H.; Matsushita, H.; Kobayashi, H.; Ikeda, Y.; Kizaki, M. A novel therapeutic technology of specific RNA inhibition for acute promyelocytic leukemia: Improved design of maxizymes against PML/RAR $\alpha$ mRNA. Int. J. Oncol. 2002, 20, 127-130. [CrossRef] [PubMed]

13. Kobayashi, H.; Dorai, T.; Holland, J.F.; Ohnuma, T. Cleavage of human MDR1 mRNA by a hammerhead ribozyme. FEBS Lett. 1993, 319, 71-74. [CrossRef]

14. Kobayashi, H.; Takemura, Y.; Miyachi, H.; Skelton, L.; Jackman, A.L. Effect of hammerhead ribozyme against human thymidylate synthase on the cytotoxicity of thymidylate synthase inhibitors. Jpn. J. Cancer Res. 1995, 86, 1014-1018. [CrossRef] [PubMed]

15. Wang, F.-S.; Kobayashi, H.; Liang, K.-W.; Holland, J.F.; Ohnuma, T. Retrovirus-mediated transfer of anti-MDR1 ribozymes fully restores chemosensitivity of P-glycoprotein-expressing human lymphoma cells. Hum. Gene Ther. 1999, 10, 1185-1195. [CrossRef] [PubMed]

16. Li, X.-K.; Kobayashi, H.; Holland, J.F.; Ohnuma, T. Expression of dihydrofolate reductase and multidrug resistance genes in trimetrexate-resistant human leukemia cell lines. Leuk. Res. 1993, 17, 483-490. [CrossRef]

17. Miyachi, H.; Ma, L.; Takemura, Y.; Kobayashi, H.; Hirahara, I.; Sonehara, H.; Ando, Y. Microsatellite instability and clonal heterogeneity of MDR1 messenger RNA expression in trimetrexate-resistant human leukemia molt-3 cells developed in thymidine. Int. J. Cancer 1999, 82, 63-69. [CrossRef]

18. Takemura, Y.; Kobayashi, H.; Miyachi, H. Variable expression of the folylpolyglutamate synthetase gene at the level of mRNA transcription in human leukemia cell lines sensitive, or made resistant, to various antifolate drugs. Anti-Cancer Drugs 1999, 10, 677-684. [CrossRef] [PubMed]

19. Asai, S.; Miyachi, H.; Kobayashi, H.; Takemura, Y.; Ando, Y. Large diversity in transport-mediated methotrexate resistance in human leukemia cell line CCRF-CEM established in a high concentration of leucovorin. Cancer Sci. 2003, 94, 210-214. [CrossRef] [PubMed]

20. Kobayashi, H.; Kim, N.; Halatsch, M.-E.; Ohnuma, T. Specificity of ribozyme designed for mutated DHFR mRNA. Biochem. Pharmacol. 1994, 47, 1607-1613. [CrossRef]

21. Komiyama, T.; Ogura, A.; Hirokawa, T.; Zhijing, M.; Kamiguchi, H.; Asai, S.; Miyachi, H.; Kobayashi, H. Analysis to Estimate Genetic Variations in the Idarubicin-Resistant Derivative MOLT-3. Int. J. Mol. Sci. 2016, 18, 12. [CrossRef] [PubMed]

22. Cingolani, P.; Platts, A.; Wang, L.L.; Coon, M.; Nguyen, T.; Wang, L.; Land, S.J.; Lu, X.; Ruden, D.M. A program for annotating and predicting the effects of single nucleotide polymorphisms, SnpEff: SNPs in the genome of Drosophila melanogaster strain $\mathrm{w}^{1118}$; iso-2; iso-3. Fly 2012, 6, 80-92. [CrossRef] [PubMed]

23. Showel, M.M.; Levis, M. Advances in treating acute myeloid leukemia. F1000prime Rep. 2014, 6, 96. [CrossRef] [PubMed]

24. Murtaza, M.; Dawson, S.-J.; Tsui, D.W.; Gale, D.; Forshew, T.; Piskorz, A.M.; Parkinson, C.; Chin, S.F.; Kingsbury, Z.; Wong, A.S.; et al. Non-invasive analysis of acquired resistance to cancer therapy by sequencing of plasma DNA. Nature 2013, 497, 108-112. [CrossRef] [PubMed]

25. Gonzalez de Castro, D.; Clarke, P.; Al-Lazikani, B.; Workman, P. Personalized cancer medicine: Molecular diagnostics, predictive biomarkers, and drug resistance. Clin. Pharmacol. Ther. 2013, 93, 252-259. [CrossRef] [PubMed]

26. Youk, J.; Koh, Y.; Park, H.; Kim, D.-Y.; Lee, C.-S.; Lee, J.; Kim, H.J.; Yoon, H.-J.; Ahn, K.-S.; Jung, J.-S.; et al. Mutation in Retinoic X Receptor- $\gamma$ Is a Possible Mechanism of All-Trans Retinoic Acid Resistance in Acute Promyelocytic Leukemia (APL): Identifying Genetic Changes Related to Drug Resistance in APL Using Whole Exome Sequencing. Blood 2014, 124, 2358.

27. Lam, S.S.Y.; Cher, C.Y.; Ng, N.K.; Man, C.H.; Leung, A.Y. Whole Exome Sequencing of FLT3-ITD Sorafenib-Resistant Acute Myeloid Leukaemia. Blood 2015, 126, 1400.

28. Karjalainen, R.; Eldfors, S.; Edgren, H.; Venkata, N.P.K.; Kontro, M.; Majumder, M.M.; Murumägi, A.; Parsons, A.; Almusa, H.; Ellonen, P.; et al. Exome sequencing reveals both DNA sequence and copy number changes in AML: Potential driver changes and mechanisms of drug resistance revealed from serial samples from the same patients. Cancer Res. 2012, 72 (Suppl. 8), 5067. [CrossRef]

29. De Keersmaecker, K.; Atak, Z.K.; Li, N.; Vicente, C.; Patchett, S.; Girardi, T.; Gianfelici, V.; Geerdens, E.; Clappier, E.; Porcu, M.; et al. Exome sequencing identifies mutation in CNOT3 and ribosomal genes RPL5 and RPL10 in T-cell acute lymphoblastic leukemia. Nat. Genet. 2013, 45, 186-190. [CrossRef] [PubMed] 
30. Andersson, E.; Pemovska, T.; Lauhio, A.; Pietarinen, P.; Mateos, C.; Faber, E.; Brümmendorf, T.; Kallioniemi, O.; Wennerberg, K.; Mustjoki, S. 826: Primary T-prolymphocytic leukemia (T-PLL) cells are sensitive to BCL-2 and HDAC inhibitors: Results from high-throughput ex vivo drug testing. Eur. J. Cancer 2014, 50, S200. [CrossRef]

31. Woyach, J.A.; Furman, R.R.; Liu, T.-M.; Ozer, H.G.; Zapatka, M.; Ruppert, A.S.; Xue, L.; Li, D.H.-H.; Steggerda, S.M.; Versele, M.; et al. Resistance mechanisms for the Bruton's tyrosine kinase inhibitor ibrutinib. N. Engl. J. Med. 2014, 370, 2286-2294. [CrossRef] [PubMed]

32. Smeets, M.; Raymakers, R.; Vierwinden, G.; Pennings, A.; Boezeman, J.; Minderman, H.; de Witte, T.M. Idarubicin DNA intercalation is reduced by MRP1 and not Pgp. Leukemia 1999, 13, 1390. [CrossRef] [PubMed]

33. GATK tool. Available online: https://www.broadinstitute.org/gatk/ (accessed on 20 July 2018).

34. SnpEff program. Available online: http://snpeff.sourceforge.net/ (accessed on 20 July 2018).

35. Kanehisa, M.; Goto, S. KEGG: Kyoto encyclopedia of genes and genomes. Nucl. Acids Res. 2000, 28, 27-30. [CrossRef] [PubMed]

36. GOrilla tool. Available online: http://cbl-gorilla.cs.technion.ac.il/ (accessed on 20 July 2018).

37. Eden, E.; Navon, R.; Steinfeld, I.; Lipson, D.; Yakhini, Z. GOrilla: A tool for discovery and visualization of enriched GO terms in ranked gene lists. BMC Bioinf. 2009, 10, 48. [CrossRef] [PubMed]

38. The Cancer Chemotherapy Center. Available online: http://www.jfcr.or.jp/english/chemotherapy (accessed on 20 July 2018).

39. Hu, E.; Liang, P.; Spiegelman, B.M. AdipoQ is a novel adipose-specific gene dysregulated in obesity. J. Biol. Chem. 1996, 271, 10697-10703. [CrossRef] [PubMed]

40. Fruebis, J.; Tsao, T.-S.; Javorschi, S.; Ebbets-Reed, D.; Erickson, M.R.S.; Yen, F.T.; Bihain, B.E.; Lodish, H.F. Proteolytic cleavage product of 30-kDa adipocyte complement-related protein increases fatty acid oxidation in muscle and causes weight loss in mice. Proc. Natl. Acad. Sci. USA 2001, 98, 2005-2010. [CrossRef] [PubMed]

41. Kadowaki, T.; Yamauchi, T.; Kubota, N.; Hara, K.; Ueki, K.; Tobe, K. Adiponectin and adiponectin receptors in insulin resistance, diabetes, and the metabolic syndrome. J. Clin. Investig. 2006, 116, 1784-1792. [CrossRef] [PubMed]

42. Eckardt, K.; Taube, A.; Eckel, J. Obesity-associated insulin resistance in skeletal muscle: Role of lipid accumulation and physical inactivity. Rev. Endocr. Metab. Disord. 2011, 12, 163-172. [CrossRef] [PubMed]

43. Flachs, P.; Mohamed-Ali, V.; Horakova, O.; Rossmeisl, M.; Hosseinzadeh-Attar, M.; Hensler, M.; Ruzickova, J.; Kopecky, J. Polyunsaturated fatty acids of marine origin induce adiponectin in mice fed a high-fat diet. Diabetologia 2006, 49, 394-397. [CrossRef] [PubMed]

44. Chen, M.B.; McAinch, A.J.; Macaulay, S.L.; Castelli, L.A.; O’Brien, P.E.; Dixon, J.B.; Cameron-Smith, D.; Kemp, B.E.; Steinberg, G.R. Impaired activation of AMP-kinase and fatty acid oxidation by globular adiponectin in cultured human skeletal muscle of obese type 2 diabetics. J. Clin. Endocrinol. Metab. 2005, 90, 3665-3672. [CrossRef] [PubMed]

45. Wu, Y.; Li, Y.; Lange, E.M.; Croteau-Chonka, D.C.; Kuzawa, C.W.; McDade, T.W.; Qin, L.; Curocichin, G.; Borja, J.B.; Lange, L.A.; et al. Genome-wide association study for adiponectin levels in Filipino women identifies CDH13 and a novel uncommon haplotype at KNG1-ADIPOQ. Hum. Mol. Genet. 2010, 19, 4955-4964. [CrossRef] [PubMed]

46. Enns, J.E.; Taylor, C.G.; Zahradka, P. Variations in adipokine genes AdipoQ, Lep, and LepR are associated with risk for obesity-related metabolic disease: The modulatory role of gene-nutrient interactions. J. Obes. 2011, 2011, 168659. [CrossRef] [PubMed]

47. Warodomwichit, D.; Shen, J.; Arnett, D.K.; Tsai, M.Y.; Kabagambe, E.K.; Peacock, J.M.; Hixson, J.E.; Straka, R.J.; Province, M.A.; An, P.; et al. ADIPOQ polymorphisms, monounsaturated fatty acids, and obesity risk: The GOLDN study. Obesity 2009, 17, 510-517. [CrossRef] [PubMed]

48. Saltiel, A.R.; Kahn, C.R. Insulin signalling and the regulation of glucose and lipid metabolism. Nature 2001, 414, 799-806. [CrossRef] [PubMed]

49. Biswas, S.K.; Mantovani, A. Orchestration of metabolism by macrophages. Cell Metab. 2012, 15, $432-437$. [CrossRef] [PubMed]

50. Xu, C.; Lin, F.; Qin, S. Relevance between lipid metabolism-associated genes and rat liver regeneration. Hepatol. Res. 2008, 38, 825-837. [CrossRef] [PubMed] 
51. Martinez, F.O.; Gordon, S.; Locati, M.; Mantovani, A. Transcriptional profiling of the human monocyte-tomacrophage differentiation and polarization: New molecules and patterns of gene expression. J. Immunol. 2006, 177, 7303-7311. [CrossRef] [PubMed]

52. Amirian, E.S.; Ittmann, M.M.; Scheurer, M.E. Associations between arachidonic acid metabolism gene polymorphisms and prostate cancer risk. Prostate 2011, 71, 1382-1389. [CrossRef] [PubMed]

53. Todur, S.P.; Ashavaid, T.F. Association of sp1 tandem repeat polymorphism of alox 5 with coronary artery disease in indian subjects. Clin. Transl. Sci. 2012, 5, 408-411. [CrossRef] [PubMed]

54. Kaklamani, V.G.; Wisinski, K.B.; Sadim, M.; Gulden, C.; Do, A.; Offit, K.; Baron, J.A.; Ahsan, H.; Mantzoros, C.; Pasche, B. Variants of the adiponectin $(A D I P O Q)$ and adiponectin receptor 1 (ADIPOR1) genes and colorectal cancer risk. JAMA 2008, 300, 1523-1531. [CrossRef] [PubMed]

55. Cui, E.; Deng, A.; Wang, X.; Wang, B.; Mao, W.; Feng, X.; Hua, F. The role of adiponectin (ADIPOQ) gene polymorphisms in the susceptibility and prognosis of non-small cell lung cancer. Biochem. Cell Biol. 2011, 89, 308-313. [CrossRef] [PubMed]

56. Xu, Y.; He, B.; Pan, Y.; Gu, L.; Nie, Z.; Chen, L.; Li, R.; Gao, T.; Wang, S. The roles of $A D I P O Q$ genetic variations in cancer risk: Evidence from published studies. Mol. Biol. Rep. 2013, 40, 1135-1144. [CrossRef] [PubMed]

57. Habermann, N.; Ulrich, C.M.; Lundgreen, A.; Makar, K.W.; Poole, E.M.; Caan, B.; Kulmacz, R.; Whitton, J.; Galbraith, R.; Potter, J.D.; et al. PTGS1, PTGS2, ALOX5, ALOX12, ALOX15, and FLAP SNPs: Interaction with fatty acids in colon cancer and rectal cancer. Genes Nutr. 2013, 8, 115-126. [CrossRef] [PubMed]

58. Budinska, E.; Popovici, V.; Tejpar, S.; D’Ario, G.; Lapique, N.; Sikora, K.O.; Di Narzo, A.F.; Yan, P.; Hodgson, J.G.; Weinrich, S.; et al. Gene expression patterns unveil a new level of molecular heterogeneity in colorectal cancer. J. Pathol. 2013, 231, 63-76. [CrossRef] [PubMed]

59. Chen, Y.; Li, D.; Li, S. The Alox5 gene is a novel therapeutic target in cancer stem cells of chronic myeloid leukemia. Cell Cycle 2009, 8, 3488-3492. [CrossRef] [PubMed]

60. Chen, Y.; Hu, Y.; Zhang, H.; Peng, C.; Li, S. Loss of the Alox5 gene impairs leukemia stem cells and prevents chronic myeloid leukemia. Nat. Genet. 2009, 41, 783-792. [CrossRef] [PubMed]

61. DeKelver, R.C.; Lewin, B.; Lam, K.; Komeno, Y.; Yan, M.; Rundle, C.; Lo, M.-C.; Zhang, D.-E. Cooperation between RUNX1-ETO9a and novel transcriptional partner KLF6 in upregulation of Alox5 in acute myeloid leukemia. PLoS Genet 2013, 9, e1003765. [CrossRef] [PubMed]

62. Wang, J.; Ma, D.; Wang, P.; Wu, W.; Cao, L.; Lu, T.; Zhao, J.; Fang, Q. Alox-5 As a Potent Therapeutic Target on Overcoming TKI-Resistance in Chronic Myeloid Leukemia with T315I Mutation in Bcr-Abl. Blood 2015, $126,4835$.

63. Lucas, C.M.; Harris, R.J.; Giannoudis, A.; McDonald, E.; Clark, R.E. Low leukotriene B4 receptor 1 leads to ALOX5 downregulation at diagnosis of chronic myeloid leukemia. Haematologica 2014, 99, 1710-1715. [CrossRef] [PubMed]

64. Al Baghdadi, T.; Abonour, R.; Boswell, H.S. Novel combination treatments targeting chronic myeloid leukemia stem cells. Clin. Lymphoma Myeloma Leuk. 2012, 12, 94-105. [CrossRef] [PubMed]

65. Chomel, J.-C.; Turhan, A.G. Chronic myeloid leukemia stem cells in the era of targeted therapies: Resistance, persistence and long-term dormancy. Oncotarget 2011, 2, 713-727. [CrossRef] [PubMed]

66. Naka, K.; Hoshii, T.; Hirao, A. Novel therapeutic approach to eradicate tyrosine kinase inhibitor resistant chronic myeloid leukemia stem cells. Cancer Sci. 2010, 101, 1577-1581. [CrossRef] [PubMed]

67. Hamad, A.; Sahli, Z.; El Sabban, M.; Mouteirik, M.; Nasr, R. Emerging therapeutic strategies for targeting chronic myeloid leukemia stem cells. Stem Cells Int. 2013, 2013, 724360. [CrossRef] [PubMed]

68. Bhalla, K.; Hindenburg, A.; Taub, R.N.; Grant, S. Isolation and characterization of an anthracycline-resistant human leukemic cell line. Cancer Res. 1985, 45, 3657-3662. [PubMed]

(C) 2018 by the authors. Licensee MDPI, Basel, Switzerland. This article is an open access article distributed under the terms and conditions of the Creative Commons Attribution (CC BY) license (http:/ / creativecommons.org/licenses/by/4.0/). 